Article

\title{
Dynamic Supply Chain Design and Operations Plan for Connected Smart Factories with Additive Manufacturing
}

\author{
Byung Do Chung ${ }^{1, *}$, Sung Il Kim ${ }^{2}$ and Jun Seop Lee ${ }^{3}$ \\ 1 Department of Industrial Engineering, Yonsei University, 50 Yonsei-ro, Seodaemun-gu, Seoul 03722, Korea \\ 2 AI Platform Development Team, LG Uplus, 32 Hangang-daero, Yongsan-gu, Seoul 04389, Korea; \\ sung1eo@hanmail.net \\ 3 Department of Industrial Engineering, Yonsei University, 50 Yonsei-ro, Seodaemun-gu, Seoul 03722, Korea; \\ wnstjq322@naver.com \\ * Correspondence: bd.chung@yonsei.ac.kr; Tel.: +82-2-2123-3875; Fax: +82-2-364-7807
}

Received: 4 March 2018; Accepted: 5 April 2018; Published: 8 April 2018

\begin{abstract}
Interest in smart factories and smart supply chains has been increasing, and researchers have emphasized the importance and the effects of advanced technologies such as 3D printers, the Internet of Things, and cloud services. This paper considers an innovation in dynamic supply-chain design and operations: connected smart factories that share interchangeable processes through a cloud-based system for personalized production. In the system, customers are able to upload a product design file, an optimal supply chain design and operations plan are then determined based on the available resources in the network of smart factories. The concept of smart supply chains is discussed and six types of flexibilities are identified, namely: design flexibility, product flexibility, process flexibility, supply chain flexibility, collaboration flexibility, and strategic flexibility. Focusing on supply chain flexibility, a general planning framework and various optimization models for dynamic supply chain design and operations plan are proposed. Further, numerical experiments are conducted to analyze fixed, production, and transportation costs for various scenarios. The results demonstrate the extent of the dynamic supply chain design and operations problem, and the large variation in transportation cost.
\end{abstract}

Keywords: connected smart factories; additive manufacturing; dynamic supply chain design; flexibility; customized demand

\section{Introduction}

In the era of mass production, manufacturing companies have emphasized the efficiency of processes such as procurement, production, and logistics, in order to minimize the cost of over- and under-stocking. To improve productivity and reduce costs, companies have focused on economies of scale, and analyzed the tradeoffs between different processes. As the importance of personalized customer needs increases and the product life cycle became shorter, more companies are focusing upon customized products and flexibility. Production and supply chain management (SCM) systems, such as lean and agile systems, have been introduced by many companies [1,2].

The manufacturing system that provides customized products has been discussed and implemented. In particular, a manufacturing paradigm of mass customization has been in place since the late 1980s. Even though there has been controversy over the level of individualization [1], mass customization has been implemented by several important concepts, including product family architecture, reconfigurable manufacturing system, and delaying differentiation [3]. Now, we are entering a new era, which demands a new manufacturing paradigm, focusing on highly customized 
products, such as economies of one [4] and make-to-individual production [5]. Therefore, with the adoption of new information and communication technology (ICT), developing new production and SCM systems that support personalized manufacturing has become an matter of urgency [6].

Many governments and manufacturing companies have been developing more automated and flexible systems, in order to provide customized products. In Germany for example, the Industry 4.0 strategy was announced, and the concept of the smart factory was introduced by integrating new ICT technology and manufacturing systems. With advanced ICT technologies such as the Internet of Things (IoT), cloud computing, data analytics, and 3D printers, we are able to develop new manufacturing and supply chain systems that are tailored to meet individualized requirements [7]. In such environments, equipment in a smart factory is connected by the IoT, and monitored and shared in a cloud system. When multiple factories are connected and shared, they become connected smart factories, or a web of smart factories. In a traditional manufacturing system, it may be difficult to share processes and facilities; however, in an environment of connected smart factories, it is possible to share factories in real time and create new business models [8]. Customers and other players in a supply chain can be connected and efficiently communicate through a cloud-based system. To test and implement the new supply chain, the EU implemented the ManuCloud project, to share the manufacturing capacity of production networks in the cloud architecture [9]. In Korea, connected smart factories with 3D printers supporting personalized production have been built in Daejeon, Gwangju, and other cities, and are managed in the cloud system under the name "Factory as a Service" (FaaS) [10]. Figure 1a shows the layout of the smart factory. 3D printers and post-processing facilities are located at the side of the octagon, while a robot arm in the center moves products. The factory in each city has interchangeable processes which can be shared when connected to the cloud system. Figure $1 \mathrm{~b}$ shows the FaaS cloud system with which customers can upload computer-aided design (CAD) files of products, collaborate with engineers, and request production. The motivation for this research is a desire to develop a dynamic supply chain design and planning applications for connected smart factories, with additive manufacturing.

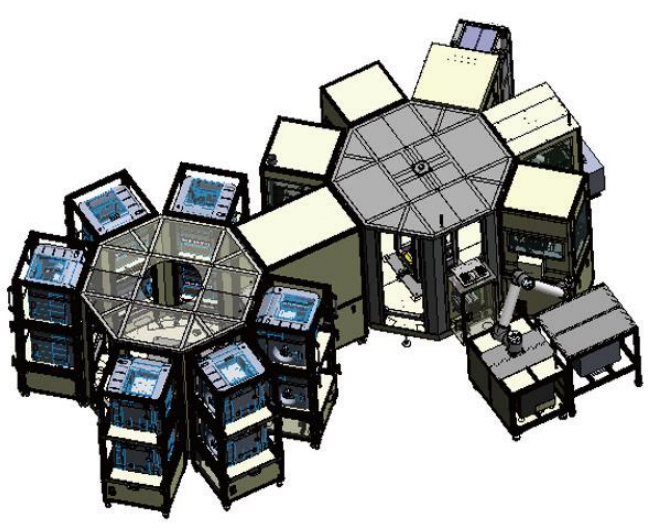

(a)

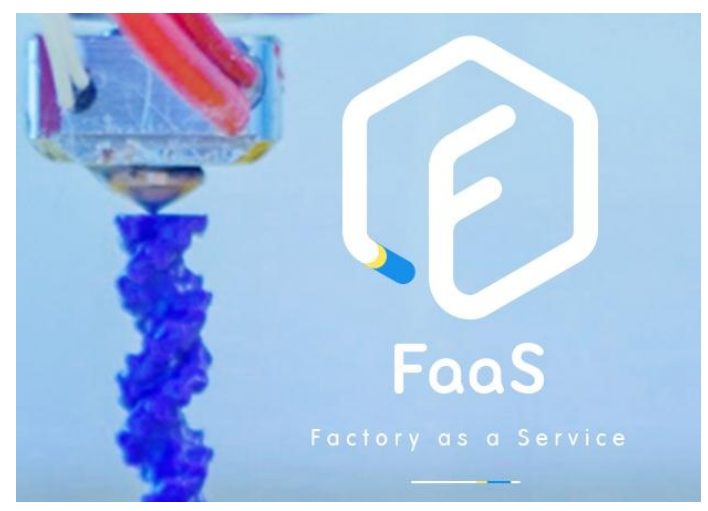

(b)

Figure 1. Connected smart factories and the cloud system. (a) Smart Factory; (b) Cloud System.

Theory and applications in SCM have been developed according to changes in manufacturing and business environments. Traditionally, the topics in SCM are classified into design and operation, and control aspects [11,12]. Supply chain design aspects deal with network configuration, outsourcing, and capacity decisions; these are long-term concerns for which changes in decisions have significant financial implications. Therefore, traditional supply chains are not frequently modified. Once a supply chain is designed according to the objective of the company, it is fixed for several months or years. Supply chain operation and control aspects are addressed after design decisions have been made. Medium and short term forecasting, production planning, and subcontracting are examples of 
operations and control issues. However, due to the aforementioned changes in business environments, a new approach is needed for dynamically designing supply chain, in order to efficiently support personalized production. In this paper, we consider a network design problem as a short-term decision based on real time data, including capacity and demand. The main contributions of the paper are as follows:

- In this paper, six types of flexibility associated with a network of smart factories utilizing 3D printers, cloud computing, and the IoT, are identified and defined. Specifically, design flexibility, product flexibility, process flexibility, supply chain flexibility, collaboration flexibility, and strategic flexibility are explained, based on a review of previous research.

- This paper proposes a general planning framework and two optimization models for supply chain design and operation, by dynamically connecting smart factories according to customer demand.

- This paper demonstrates a way of managing a network of smart factories to deal with customized products, and demonstrates the performance of the proposed approach with some scenarios.

The remainder of this paper is organized as follows. In Section 2, smart supply chains are described and the relevant literature is reviewed. Six types of flexibility are identified and explained with several examples. Papers considering mathematical models on supply chains with additive manufacturing are also reviewed. In Section 3, a general planning framework to solve the design and operations problems of a smart supply chain is presented. Optimization models are developed for selecting appropriate processes in the network of smart factories, and to generate efficient production and logistics plans using the selected processes. Numerical experiments are described in Section 4, and Section 5 concludes the paper.

\section{Smart Supply Chain with Additive Manufacturing}

\subsection{The Concept of Smart Supply Chains}

As customized products increase, companies require the ability to produce a variety of products and form an integrated network in order to efficiently utilize geographically distributed resources. A network providing customized products according to customer needs was proposed as the smart supply chain concept [13]. Later, Noori and Lee [14] focused on the role of small- and medium-sized enterprises (SMEs) in competing with big companies. Geographically spread but electronically linked SMEs could form a dynamic and adaptive network without obligatory egalitarian responsibility, which is different from traditional collaborative networks. The dynamic and adaptive network is referred to as a dispersed manufacturing network. Similar concepts of connecting companies to generate collaborative and competitive organizations include collaborative networks [15,16], responsive supply chains [17], and distributed manufacturing [18].

The concept of the smart supply chain is not new and has been discussed by many researchers and practitioners; however, recent research emphasizes the role of advanced ICT. Gaynor et al. [19] is one of the earlier works that proposes a smart supply chain using wireless sensors. As an example, they developed a prototype application to handle Sears' customized orders. Bendavid and Cassivi [20] suggest that the next step in the development of wireless sensors is the higher-level integration of inter-organizations, and e-commerce within a self-managed smart supply chain. In subsequent research, Bendavid and Cassivi [21] show how radio-frequency identification (RFID) could be adopted to implement smart supply chain models to deal with their dynamic nature. Ivanov and Sokolov [22] consider the next generation supply chain as a cyber-physical system (CPS)—an advanced network using a physical system and cloud service. They emphasize that a pre-determined supply chain structure will evolve into a dynamic and temporary network. The customer-centered new supply chain is more flexible, adaptable, and intelligent, so that it could operate without human involvement.

Butner [23] claims that a smarter supply chain has three properties: (1) instrumented-more data in a supply chain would be generated by various devices such as sensors, RFID, and actuators; 
(2) interconnected-more objects in a supply chain would be extensively connected and lead to massive collation among them; and (3) intelligent-more intelligent systems would help people by making real-time decisions and predicting future events. Recently, Wu et al. [24] added three additional characteristics, including automated, integrated, and innovative.

This paper focuses on the flexibility and dynamics required to make customized products, which could be achieved by employing new ICT such as sensors, 3D-printers, CPS, and IoT. It considers a set of geographically dispersed smart factories sharing their machines and collaborating to make customized products through a cloud system—called connected smart factories. They are able to share machines through entire processes, or partially share some processes to make a customized product. Then, smart supply chains could be dynamically organized to fulfill a customer order and dissolve after order fulfillment, using the advanced ICT mentioned above.

\subsection{Flexibility in the Smart Supply Chain with Additive Manufacturing}

With advanced ICT, the smart supply chain could be more flexible than the traditional supply chain. There are many ways to implement a smart supply chain. For example, traditional production facilities with smart software systems can be a part of a smart supply chain. With anticipatory shipping models, a company is able to deal with individual customer's requirement. In this paper, we focus on the flexibilities achieved by connected smart factories with additive manufacturing that can be shared via a cloud system. A literature review was conducted to identify the flexibilities, which have been classified into six categories. Note that the purpose of the paper is not to thoroughly review the smart supply chain literature, but to identify smart supply chain flexibilities with 3D printing and other interchangeable processes.

\subsubsection{Design Flexibility}

A 3D printer using additive manufacturing technology adds layers using raw materials such as polymers, ceramics, and metals [25]. 3D printers can produce products in the desired shape without molds when the raw materials necessary for the production are ready; the variety of product shapes is therefore very broad. Design flexibility refers to the flexibility to produce a product with a variety of designs. 3D printers can be used to produce customized products with various designs performing the same function [4].

Production through 3D printouts can be based on CAD drawings, and do not require expensive tools used for subtractive manufacturing processes such as drilling, grinding, and molding [26]. The process of product design is less constrained by manufacturing processes, and has a high degree of freedom. With 3D printers, hollow-core structures are easily formed while maintaining or optimizing the characteristics and performance of products. For example, Lu et al. [27] propose a honeycomb-cell structure providing strength in tension with minimal material cost. Qin et al. [28] investigate the properties of spider web design. These new types of design allow companies to make products that perform the same function while reducing the weight of the parts compared to solid type designs, through topology optimization $[29,30]$. Moreover, in order to manufacture lighter parts, fewer raw materials are used and a manufacturer can save on raw materials costs. Lighter products consume less energy and produce less $\mathrm{CO}_{2}$, and are therefore of significant interest to companies in automobiles and aviation.

\subsubsection{Product Flexibility}

Product flexibility means that a variety of products can be produced in one factory or supply chain according to customers' requirements. This concept is closely related to mass customization [1], but with some differences. While a traditional mass customization system is based on modular design or product postponement [31], mass customization in the smart supply chain is based on CPS and the Internet of Things and Services in the manufacturing system [7]. In addition, in contrast to traditional systems, it does not require a high degree of supply chain integration [26]. 
3D printers also play an important role in meeting individual customer requirements. In the past, 3D printers were mainly used for prototype and mockup production at low cost. However, due to the development and spread of technology, 3D printers are increasingly being used. Rather than using a single product, companies can test market response with small quantities of finished products of various sizes, colors, and functions [7,32]. In addition, 3D printers are successfully used to produce customized final products with individual product designs without retooling $[29,33]$. In this way, it is of the greatest advantage to be able to flexibly produce small quantities of various products without incidental tooling costs through 3D printing [34,35]. If the raw materials of the products to be printed are the same, any product could be produced in a factory.

\subsubsection{Process Flexibility}

Flexibility is needed to adapt to the wide variety of changes that occur at the process level of the production site in the manufacture of personalized products [36]. Process flexibility means that the same product can be produced through different manufacturing processes.

With the production line using 3D printers, process flexibility can be achieved so that one product can be produced in various ways. In other words, depending on the equipment or resources that are available, manufacturers could flexibly select the best process to make the product. First, the product can be redesigned to produce finished products with fewer components, requiring less assembly processes [37,38]. For example, GE Aviation used to produce fuel nozzles through the assembly of 20 parts. Now, they produce them as single units using additive manufacturing. Secondly, the performance of $3 \mathrm{D}$ printers could also affect the selection of the manufacturing process. For example, a large 3D printer produces a single product at a time, while a small 3D printer produces parts of the product that are assembled in the subsequent process. Thirdly, the manufacturing process depends on the selection of material. Typically, polymers require a limited finishing process while metals require post-processes [4].

\subsubsection{Supply Chain Flexibility}

The development of advanced technology can change the supply chain configuration, or could require the adoption of a new supply chain model [26,35]. Supply chain flexibility means that facilities in the connected smart factories are shared and operated flexibly. In the smart factory environment, supply chain flexibility can be achieved through outsourcing of manufacturing, which has become easier with the use of 3D printers [26], real time data collection, and agile collaboration between intelligent agents [39]. In addition, cyber-supported collaboration infrastructure plays an important role in sharing demand and capacity among enterprises in a collaborative network [40].

Further, the large variety of products that result from customization introduces significant uncertainty. It is possible to flexibly cope with such high supply chain uncertainties by sharing the capacity of the facilities in the network [41]. With advanced technology, collaborative manufacturing is considered to be a new business model [42]. If the capacity of a particular process in the factory is insufficient, a product can be made by using the capacity of other factories in the network, through sharing processes and machines. That is, available resources in the supply chain network can be used efficiently, and the capacity utilization of factories in the network can be maximized [43].

\subsubsection{Collaboration Flexibility}

Previous studies have emphasized that collaboration through information sharing within the supply chain has a significant impact on supply chain performance [44,45]. In recent years, with the introduction of new technologies and extensive connectivity, the amount and speed of information generated in the supply chain have become more diverse and faster than ever before. Product design, production, and product tracking information is collected in various ways, including RFID and the IoT, and is shared in a cloud. The cloud system monitors and stores information generated within the supply chain to provide visibility, and enables end-to-end collaboration through information 
sharing [46]. Collaboration flexibility means that supply chain participants can exchange feedback with each other and work together to provide customized products. It focuses on the integration of the design, process planning, production planning, and logistics, through information sharing, while supply chain flexibility focuses on the integration of supply stages through the sharing of available capacities.

In the traditional manufacturing environment, the roles and responsibilities of the designer and manufacturer are clearly distinguished, but in the new environment, the distinction becomes unclear [4]. In a smart supply chain, participants can collaborate from design to delivery; it extends the range of collaboration compared to the traditional approach, such as the use of concurrent engineering in the design stage. For example, even during production, a designer can request manufacturing process changes and a manufacturer can request product design changes according to the availability of equipment. Even customers who do not know how to draw a CAD model or produce a product can request production based on a purchased CAD file. Therefore, collaboration among supply chain participants is critically important; a smart supply chain should be able to support last-minute changes to individual customer requirements [7].

\subsubsection{Strategic Flexibility}

Strategic flexibility refers to the ability to respond in a timely manner to changes in market competition, and to environmental changes in an appropriate manner [47]. Many research studies have been conducted on strategic flexibility. Earlier works on strategic flexibility emphasized responsiveness. They focused on identifying characteristics and acquiring appropriate resources according to the changing environment. Appropriate implementation options were then developed [48,49]. In addition, enterprises are required to develop strategic diversity and then choose an appropriate strategy to best suit the changing environment $[50,51]$.

When it comes to the concept of the smart supply chain with additive manufacturing, new products can be quickly introduced in response to market demand [52]. Also, timely response may be achieved through coordination of flexible resources connected to cloud-based networks in response to internal or external environmental changes. Shirodkar and Kempf [53] proposed a method to adopt flexible strategies to solve the problems of internal or external uncertainties in semiconductor production. They shared the capacity of each process facility to make the plant more flexible. Generally, one product is produced in one factory, but if there is insufficient capacity due to various uncertainties, it can be produced in another factory registered in the network. Seok and Nof [43] made a supply chain network operate flexibly by maximizing the capacity utilization of factories in the network.

\subsection{Mathematical Models for Supply Chains with Additive Manufacturing}

This section summarizes the relevant research on quantitative approaches to supply chains with additive manufacturing. Recent research focuses on the adoption of additive manufacturing and its effects. Scott and Harrison [52] consider additive manufacturing in an end-to-end supply chain, to compare the performance of additive and traditional manufacturing. They propose a stochastic optimization model and show that demand is the most important factor for the adoption of new technology. Barz et al. [54] investigate the impact of additive manufacturing on the structure of the supply chain. A two-stage capacitated facility location problem is used for supply chain configuration, consisting of suppliers, manufacturers, and customers. They show that as the efficiency of the new technology increases, the effect on the supply chain configuration is significant in three scenarios: evenly distributed facilities, clustered suppliers, and clustered manufacturers. Emelogu et al. [55] propose a two-stage stochastic programming model to analyze the cost, and to investigate the economic feasibility of additive manufacturing facilities. There are few studies on the operational aspects of the smart supply chain. Ivanov et al. [56] consider a mathematical model and algorithm for a scheduling problem of a smart factory, under the consideration of different processing speeds and dynamic job arrivals. 


\section{Materials and Methods}

\subsection{Planning Framework}

Different to the mass production system, it may be more difficult or impossible to forecast highly customized products as customers and products are not known before orders are placed. Players in a supply chain providing customized products are able to know the product characteristics and the required manufacturing processes after receiving the order; these differ by product. Therefore, flexibility is more important than ever before.

Figure 2 shows the process for the smart supply chain from customer order to delivery of the product. First, the customer uploads a CAD file and requests an order via the cloud system using a website. Then, engineers supporting the system validate the CAD file, confirm whether the product can be made in the system, and provide feedback to the customer. At the same time, the required processes and bill of materials (BOM) are designed. Next, based on the design data, real time data about the machines in the processes are gathered from the IoT and monitored through the cloud system. After the required information-including availability of raw materials, capacity of resources, and working calendars-has been reviewed, the optimal supply chain design and operations plans are generated for a single order request by matching demand requirements and supply capability. Based on the decision, customers receive information on the facilities and processes that will be used, the production plan, and the delivery date. After confirmation from the customer, an operations plan is sent to the selected parties. Finally, each party in the supply chain develops his or her own schedule, and execution begins.

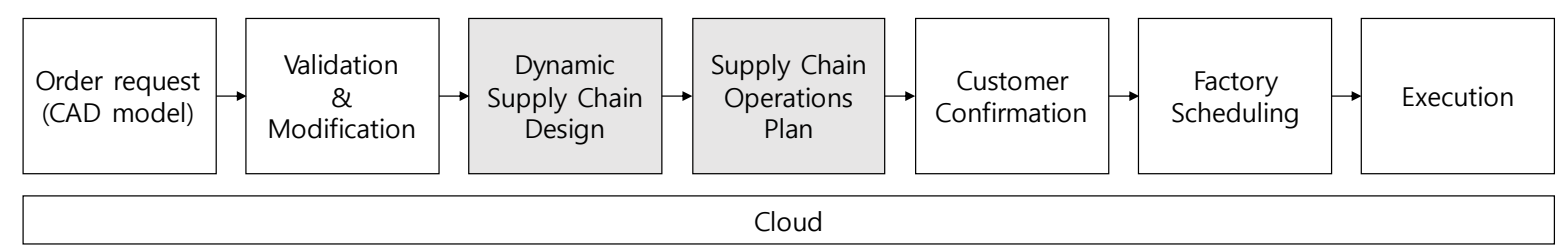

Figure 2. Smart supply chain planning process.

The optimization models in the following sections covers the steps for the development of the design and operations plan of the supply chain, which can be dynamically organized and deleted according to customer orders. It is assumed that the factories, as well as processes, are interchangeable. The example in Figure 3 explains the approach for the dynamic supply chain design and operation with connected smart factories, as proposed in this paper.

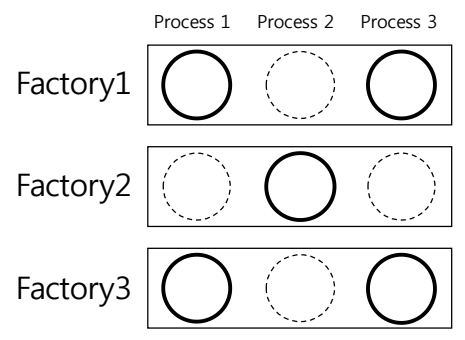

(a) Data Gathering

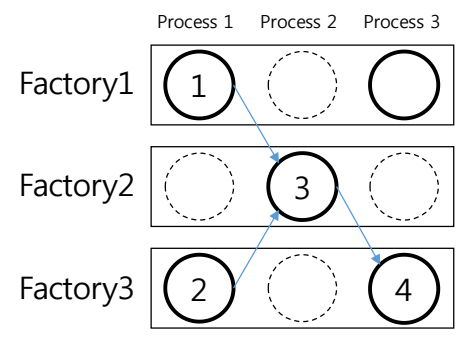

(b) Dynamic Supply Chain Design

\begin{tabular}{|l|l|l|l|l|l|}
\hline \multirow{2}{*}{ Node } & \multicolumn{5}{|c|}{ Time } \\
\cline { 2 - 6 } & 1 & 2 & 3 & 4 & 5 \\
\hline $1 \rightarrow 3$ & 2 & 1 & & & \\
\hline $2 \rightarrow 3$ & 1 & 1 & & & \\
\hline $3 \rightarrow 4$ & & & 2 & 2 & 1 \\
\hline
\end{tabular}

(c) Supply Chain Operations Plan

Figure 3. Dynamic supply chain design and operation.

In the first step, based on the data gathered from the customer and factories, all possible processes in each factory are selected, as outlined in Figure 3a. In the example, three processes, namely Processes 1,2 , and 3 , are required to produce the product. In addition, there are three available factories, namely 
Factories 1, 2, and 3, in the network. The nodes, represented by circles, show which process in which factory is available. A solid line indicates that the process in the factory is available, while a dotted line indicates unavailability. For example, Processes 1 and 3 in Factory 1 are available. After checking the availability, the optimal supply chain is designed. That is, the best combination of processes is selected in order to minimize the total cost and cover all required processes as shown in Figure $3 \mathrm{~b}$. Four processes in three factories are selected. That is, all three factories are sharing their resources to efficiently fulfill the current order. Process 3 in Factory 1 is not required to make the product, even if it is available. In the second step, optimal production and delivery plans are calculated using the processes selected in the previous step. Figure $3 \mathrm{c}$ shows the plan for each process.

\subsection{Dynamic Supply Chain Design}

The purpose of the dynamic supply chain design phase is to select the optimal combination of nodes to be used. We developed an integer programming model by modifying a set-covering problem. The concept is that all the required processes must be covered with at the minimum total cost. We assume that there are enough raw materials and no work-in-progress (WIP) in the process. The notations used in the optimization model are summarized in Table 1.

$$
\begin{gathered}
\min \sum_{k \in K} F C_{k} x_{k}+\sum_{i \in I} \sum_{k \in K}\left(S C_{i k} y_{i k}+P C_{i j} q_{i k}\right)+\sum_{i \in I} \sum_{k \in K} \sum_{l \in K} \frac{P T_{i k} q_{i k}}{\mathrm{CAP}_{i k}} T C_{j k} v_{i k l} \\
\text { s.t. } \quad \sum_{k \in K} q_{i k} \geq d \quad \forall i \\
\sum_{k \in K} a_{i k} x_{k} \geq 1 \quad \forall i \\
y_{i k} \leq a_{i k} x_{k} \quad \forall i, k \\
p_{i k} q_{i k} \leq u_{i k} C A P_{i k} y_{i k} \quad \forall i, k \\
v_{i k l} \leq y_{i k} \quad \forall i, k, l \\
v_{i k l} \leq y_{i+1 l} \quad \forall i, k, l \\
v_{i k l} \geq y_{i l}+y_{i+1 l}-1 \quad \forall i, k, l \\
x_{k}, y_{i k} \in\{0,1\} \quad \forall i, k \\
q_{i k} \geq 0, v_{i k l} \geq 0 \quad \forall i, k, l
\end{gathered}
$$

Table 1. Notations for dynamic supply chain design.

\begin{tabular}{cc}
\hline Sets & \\
$\mathrm{I}$ & Set of processes or nodes $(i \in \mathrm{I})$ \\
$\mathrm{K}$ & Set of factories $(k, l \in \mathrm{K})$ \\
Parameters & Demand for the product \\
$\mathrm{D}$ & Average time available per day for process $i$ in factory $k$ in the planning horizon \\
$C A P_{i k}$ & Utilization of process $i$ in factory $k$ \\
$u_{i k}$ & Fixed cost for selecting factory $k$ \\
$F C_{k}$ & Setup cost for process $i$ in factory $k$ \\
$S C_{i k}$ & Process cost per unit for process $i$ in factory $k$ \\
$P C_{i k}$ & Processing time per unit for process $i$ in factory $k$ \\
$P T_{i k}$ & Transportation cost from factory $k$ to factory $l$ \\
$T C_{k l}$ & Set-covering matrix representing the relationship between process $i$ and factory $k$ \\
$a_{i k}$ & Factory selection, 1 if factory $k$ is selected; 0, otherwise \\
\hline$x_{k}$ & Process selection; 1 if process $i$ in factory $k$ is selected; 0, otherwise \\
$y_{i k}$ & Pransportation selection; 1 if product from process $i$ in factory $k$ is sent to factory $l$ \\
$v_{i k l}$ & Production quantity of process $i$ in factory $k$ \\
$q_{i k}$ &
\end{tabular}


The objective function is expressed by Equation (1): it minimizes the total costs composed of fixed, production, and transportation costs. Fixed costs are incurred when a factory is selected, and the production costs are expressed as the sum of the setup cost and the production cost per unit multiplied by the production quantity. Finally, transportation costs arise when consecutive processes are carried out in different factories. Equation (2) represents the demand for a product, which requires a supply chain design. Equation (3) requires that all processes be covered, and Equation (4) indicates that the available process at a factory can be selected only if the factory is selected. Equation (5) represents a capacity constraint, and capacity is calculated in terms of available time. Equations (6) and (8) determine whether transportation between the factories is necessary or not. We note that the decision variable $v_{i k l}$ is not necessarily defined as a binary variable within the constraints. Equations (9) and (10) define the decision variables.

\subsection{Dynamic Supply Chain Operation}

Once the supply chain has been designed, the operations plan is generated. Nodes represent processes selected in the dynamic supply chain design phase. We also introduce a dummy node, $I_{d}$, so that finished products manufactured in several factories are delivered to the customer. The supply chain operations model, using the notations in Table 2, is as follows.

$$
\begin{gathered}
\min \sum_{i \in I} \sum_{j=I_{d}} \sum_{t \in T} p^{t} a_{i j} x_{i j}^{t} \\
\text { s.t. } \quad y_{i}^{t} \geq c_{i}^{t} \quad \forall i, t \\
I I_{i}^{t}=I I_{i}^{t-1}+\sum_{j \in I} a_{j i} x_{j i}^{t-L T_{j i}}-y_{i}^{t} \quad \forall i, t \\
I O_{i}^{t}=I O_{i}^{t-1}+y_{i}^{t}+\sum_{j \in I} a_{i j} x_{i j}^{t} \quad \forall i, t \\
\sum_{i \in I} \sum_{t \in T} a_{i I_{d}} x_{i I_{d}}^{t} \geq d \\
x_{i j}^{t}=0 \quad \forall(i, j) \in V, t \in T \backslash T_{d} \\
x_{i j}^{t}, y_{i}^{t}, I I_{i}^{t}, I O_{i}^{t} \geq 0 \quad \forall i, j, t
\end{gathered}
$$

Table 2. Notations for dynamic supply chain operation.

\begin{tabular}{cc}
\hline Sets & \\
\hline $\mathrm{I}$ & Set of processes or nodes $(i, j \in \mathrm{I})$ \\
$\mathrm{T}$ & Time periods $(\mathrm{t} \in \mathrm{T})$ \\
$T_{d}$ & Time periods when transportation model is available. $\left(T_{d} \subset T\right)$ \\
$\mathrm{V}$ & A pair of nodes connecting two consecutive processes in different factories \\
\hline Parameters & \\
$a_{i j}$ & Adjacency matrix resenting the relationship between processes \\
$p^{t}$ & Penalty cost having an incremental function for time \\
$c_{i}^{t}$ & Available capacity of node $i$ at time $\mathrm{t}$ \\
$L T_{i j}$ & Transportation lead time from node $i$ to node $j$ \\
$\mathrm{~d}$ & Demand for the product \\
\hline$x_{i j}^{t}$ & \\
$y_{i}^{t}$ & Quantity of product sent from node $i$ to node $j$ at time $\mathrm{t}$ \\
$I I_{i}^{t}$ & Quantity of product processed in node $i$ at time $\mathrm{t}$ \\
$I O_{i}^{t}$ & Raw material inventory level of node $i$ at time $\mathrm{t}$ \\
\hline
\end{tabular}


The objective function, Equation (11), aims to ensure that the production is finished as soon as possible by employing penalty cost, which increases with time. The objective function can be modified according to the decision maker's goal. Equation (12) limits the production quantity depending on the capacity of the process at each time unit. Equations (13) and (14) represent inventory balance equations for raw material and manufactured product at each process, respectively. $L T_{i j}$ represents the transportation lead time between processes $i$ and $j$. Equation (15) is a constraint expressing the demand of the product. Equation (16) shows that inter-factory movement is only possible when the transportation mode is available. The manufactured product in a factory can be sent to other factories when $t$ belongs to $T_{d}$. For example, all factories operate ten hours a day, and inter-factory transportation takes place at night after work hours. Equation (17) defines the decision variables.

\section{Numerical Experiments}

\subsection{Data}

Parameters related to factories and processes are randomly generated, and the data used in the numerical experiments are shown in Table 3. The processing time of the 3D printers is relatively longer than that of other processes such as painting, fumigating, and vision testing. It is assumed that the planning horizon is five days, and factories are operated 10 hours per day. Further, transportation between factories occurs at the conclusion of the $10 \mathrm{~h}$ operating day. All experiments were conducted using GAMS; the first mathematical model was solved using Baron, and the second by using CPLEX. The experiments used an Intel Core i5-6600 3.3 GHz processor and a computer with 8 GB memory.

Table 3. Data used in the experiments.

\begin{tabular}{cccc}
\hline $\boldsymbol{C A \boldsymbol { P } _ { \boldsymbol { i k } }}$ & {$[144,000,180,000]$} & $\boldsymbol{F C _ { \boldsymbol { k } }}$ & {$[5000,10,000]$} \\
\hline$u_{i k}$ & {$[0.8,1]$} & $S C_{i k}$ & {$[1000,2000]$} \\
$P T_{i k}$ (3D printing) & {$[2000,4000]$} & $P C_{i k}$ & {$[30,50]$} \\
$P T_{i k}$ (Others) & {$[500,1000]$} & $T C_{k l}$ & {$[2000,5000]$} \\
\hline
\end{tabular}

\subsection{Experimental Results}

First, six connected factories and a product requiring four processes were considered. Table 4 shows a set-covering matrix for a small-scale problem. For example, at the time of demand occurrence, the available processes in connected smart factory 1 are 1,2, and 3.

Table 4. Set covering matrix.

\begin{tabular}{llllllll}
\hline \multirow{2}{*}{$a_{i k}$} & & \multicolumn{7}{c}{ Factory } \\
\cline { 3 - 8 } & & $\mathbf{1}$ & $\mathbf{2}$ & $\mathbf{3}$ & $\mathbf{4}$ & $\mathbf{5}$ & $\mathbf{6}$ \\
\hline \multirow{2}{*}{ process } & 1 & 1 & 1 & 0 & 0 & 1 & 1 \\
& 2 & 1 & 0 & 1 & 0 & 1 & 0 \\
& 3 & 1 & 0 & 1 & 0 & 0 & 1 \\
& 4 & 0 & 1 & 1 & 1 & 0 & 0 \\
\hline
\end{tabular}

Figure 4 shows the results of dynamic supply chain design. A comparison of the demand of 1 for an individual request and the demand of 100 for the marketing test shows that different supply chains are obtained even if all data, except demand, are the same. In the case of an individual request, Factory 1 is selected for Process 1 and Factory 3 for the remaining processes. However, in the case of the marketing test, Factories 1, 2, and 3 are selected and Processes 1 and 3 are performed in parallel at multiple factories. After completing the supply chain design, a production and transportation plan is obtained with the dynamic supply chain operation model. In the first case, Process 1 is performed on the first day and the remaining processes are performed on the second day, as shown in Table 5. 
The customer can receive the product after two days. In the second case, demand is fulfilled after seven days, as shown in Table 6.

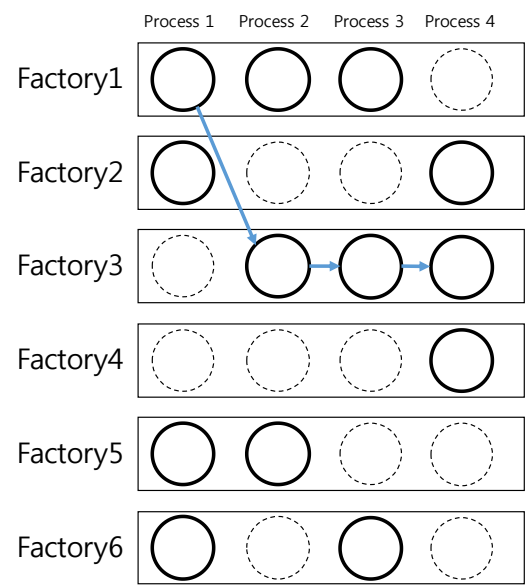

(a)

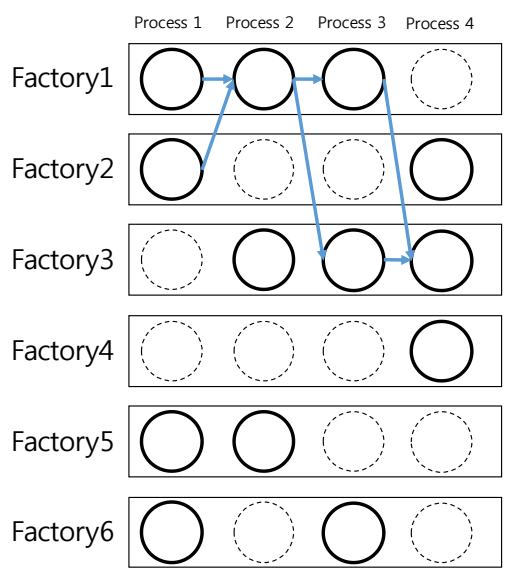

(b)

Figure 4. Dynamic supply chain design and operation. (a) Individual request; (b) Demand for marketing test.

Table 5. Production plan-Individual request.

\begin{tabular}{lccc}
\hline & Day 1 & Day 2 & Day 3 \\
\hline Process 1 (Factory 1) & 1 & 0 & 0 \\
Process 2 (Factory 2) & 0 & 1 & 0 \\
Process 3 (Factory 2) & 0 & 1 & 0 \\
Process 4 (Factory 2) & 0 & 1 & 0 \\
\hline
\end{tabular}

Table 6. Production plan-Demand for marketing test.

\begin{tabular}{cccccccc}
\hline & Day 1 & Day 2 & Day 3 & Day 4 & Day 5 & Day 6 & Day 7 \\
\hline Process 1 (Factory 1) & 10 & 10 & 10 & 10 & 10 & 3 & 0 \\
Process 1 (Factory 2) & 10 & 10 & 10 & 10 & 7 & 0 & 0 \\
Process 2 (Factory 1) & 9 & 20 & 20 & 20 & 19 & 12 & 0 \\
Process 3 (Factory 1) & 7 & 9 & 10 & 10 & 10 & 10 & 0 \\
Process 3 (Factory 3) & 0 & 2 & 8 & 10 & 10 & 10 & 4 \\
Process 4 (Factory 4) & 0 & 9 & 16 & 20 & 20 & 20 & 15 \\
\hline
\end{tabular}

\subsection{Comparison of Results}

In this section, the results are compared, considering problem size and capacity change. First, the problem size is increased by introducing more factories and more processes into the process whereby production takes place. The number of connected smart factories is increased to 12, in two separate units. In addition, the number of processes is increased to 10, in two units. Demand is fixed at 100. In all cases, the computation time required to solve each problem was less than one second. In Figure 5, the number before the parentheses represents the number of connected smart factories, and the number within parentheses represents the number of processes required. 


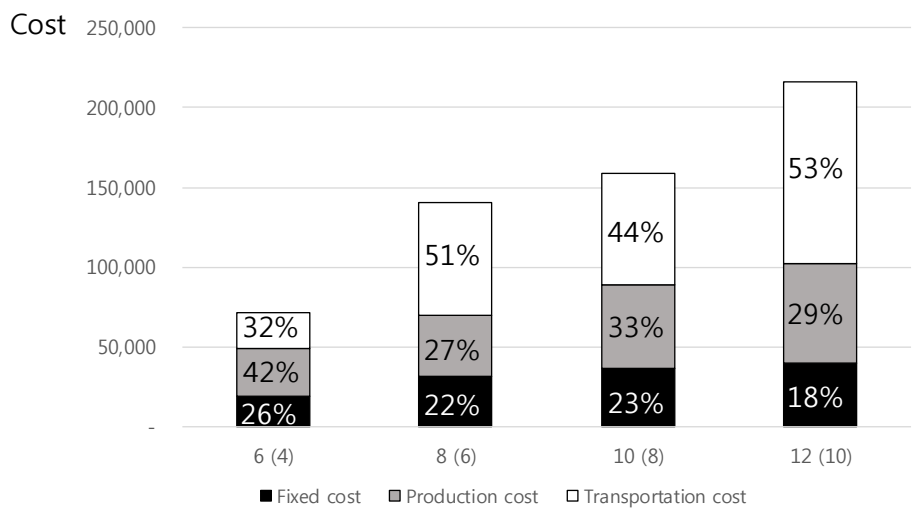

Figure 5. Cost comparison based on change in problem size.

With a demand of 100, it is observed that the total cost increases as the size of the problem increases, as shown in Figure 5. The greater the number of processes required to complete the product, the higher the total cost, with a significant increase in transportation costs. Also, it is observed that fixed costs account for a smaller proportion of total cost as the problem increases in size. Therefore, efforts should be made to reduce the number of processes required for personalized products during design.

Next, the number of processes was fixed at eight and network-connected factories at ten, to investigate the effect of a change in capacity. Figure $6 a, b$ show the structure of the supply chain that is designed for $20 \%$ less and $30 \%$ more capacity respectively. If capacity is small, more factories are needed for each process, which leads to a complicated supply chain design and an increase in cost. One interesting fact is that the supply chain or network of nodes with a larger capacity is not a subset of the supply chain with a lower capacity. Therefore, it should be emphasized that the dynamic supply chain design should be based on real-time data, including demand and available capacity.

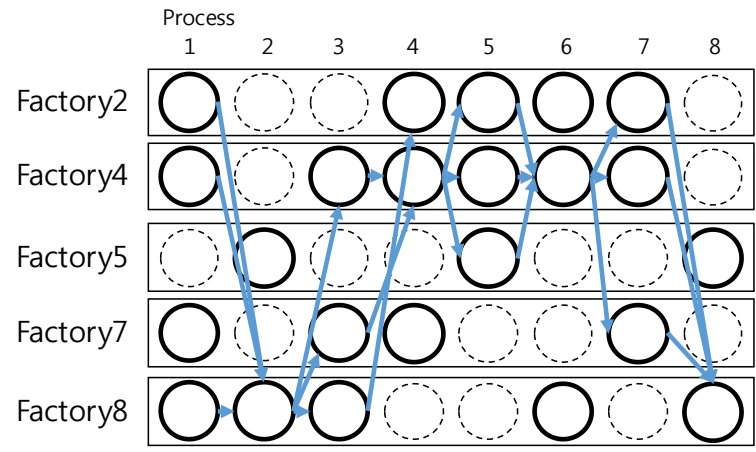

(a)

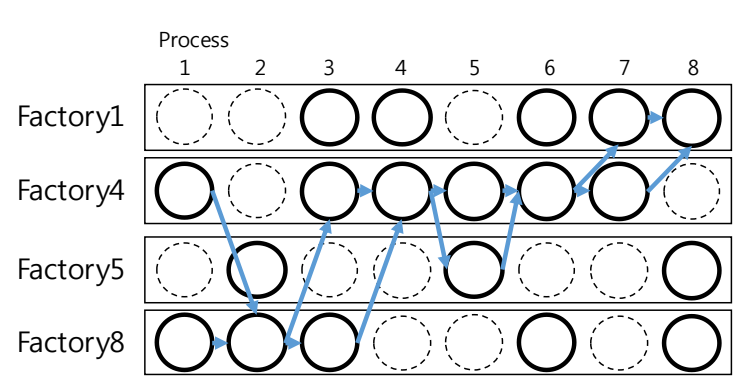

(b)

Figure 6. Dynamic supply chain design. (a) 20\% less capacity; (b) 30\% more capacity.

The cost structures of the experiments with factory capacities that vary from $-20 \%$ to $30 \%$ are shown in Figure 7. If the capacities of the factories located in the network become smaller, it becomes impossible to allocate products to less expensive factories, which increases the total cost. Because a given product can be produced in a smaller number of factories at a lower cost, the fixed cost and production cost are somewhat lower, and the transportation cost decreases significantly. For example, when we have $20 \%$ less capacity, the percentage of transportation costs is $53 \%$, while the portion of transportation cost decreases to $42 \%$ with $20 \%$ more capacity. 


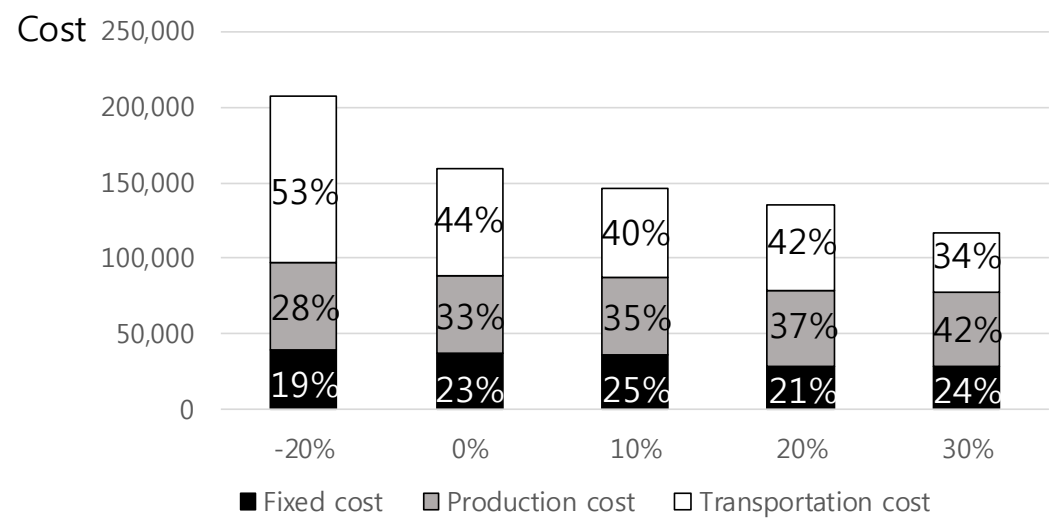

Figure 7. Cost comparison based on capacity change.

\section{Conclusions}

The development of technology is changing industries and enterprises. In contrast to traditional manufacturing practices, in a connected smart factory environment, advanced IT technologies must be integrated with manufacturing processes tailored to the production and delivery of personalized products. Since a factory cannot meet the personalized demand of all customers, a new concept of supply chain management is needed.

In this study, we investigated a smart supply chain with additive manufacturing that enables connected smart factories to communicate with each other in real time, to share data, and to make optimal decisions to support consumers through the cloud. First, we reviewed the literature related to the concept of smart supply chains, and presented six types of flexibility focusing on smart supply chains with additive manufacturing where processes are interchangeable, in order to support personalized customer requirements. These are design, product, process, supply chain, collaboration, and strategic flexibilities. Through a literature review and classification, we confirmed that a smart supply chain, especially with additive manufacturing, could provide more flexibility and opportunities in the face of the new manufacturing paradigms associated with personalized production. Also, flexibility is multi-dimensional [56] and smart supply chains can be flexible in different ways. Although the scope of this study does not cover the more comprehensive meaning of the smart supply chain, cloud-based networked manufacturing like FaaS can be one of the approaches for smart supply chains to flexibly meet individual requirements.

Next, we proposed a planning framework for dynamically designing and operating a smart supply chain, and formulated mathematical models for each stage, assuming a situation involving interchangeable factories and processes. Numerical experiments were conducted to compare the results of the proposed model under selected scenarios. Experimental results demonstrated the importance of dynamic supply chain design and operation with real time data, and showed that transportation costs vary widely. These proposed processes and results show that the smart supply chain is different from the traditional supply chain for mass production. First, in the traditional setting, the supply chain is designed as a long-term strategy [11,12]; in our model however, the supply chain is determined as a short-term plan. Second, in traditional supply chains, supply chain design is rather static and is not affected by individual orders. However, in our model, the supply chain is designed dynamically, based on the order received and available capacity at a given point of time; SMEs can be competitive with a dynamic network $[13,14]$. Third, in the smart supply chain, each customer can be involved in the supply chain design process for his or her own product [7].; this is not true of the traditional supply chain. Finally, dynamic supply chain design and operations can proactively handle the changes and uncertainties in the environments, in line with recent approaches to strategic flexibility [47].

Since the new manufacturing environment studied has not been fully implemented yet, we need to consider additional constraints on the actual environment and expand the model accordingly. In this 
study, the optimization models for dynamic supply chain design and operations were developed separately. In future research, we will develop a mathematical model that integrates the design and operation phase, and compares the results and performance with this study. Future studies will also take into account the diverse uncertainties that occur in environments where multiple factories are shared. Also, in future research, other relevant factors, such as quality of product, compatibility and pricing strategies, can be considered.

Acknowledgments: This work was supported by Institute for Information \& communications Technology Promotion(IITP) grant funded by the Korea government(MSIT) (No. 2015-0-00366, Development of Open FaaS IoT Service Platform for Mass Personalization).

Author Contributions: Byung Do Chung and Sung Il Kim conceived and designed the experiments; Byung Do Chung and Sung Il Kim performed the experiments; Byung Do Chung and Jun Seop Lee analyzed the data; Byung Do Chung wrote the paper.

Conflicts of Interest: The authors declare no conflict of interest.

\section{References}

1. Da Silveira, G.; Borenstein, D.; Fogliatto, F.S. Mass customization: Literature review and research directions. Int. J. Prod. Econ. 2001, 72, 1-13. [CrossRef]

2. Jasti, N.V.K.; Kodali, R. Lean production: Literature review and trends. Int. J. Prod. Res. 2015, 53, 867-885. [CrossRef]

3. HU, S.J. Evolving paradigms of manufacturing: From mass production to mass customization and personalization. Procedia CIRP 2013, 7, 3-8. [CrossRef]

4. Petrick, I.J.; Simpson, T.W. 3D printing disrupts manufacturing: How economies of one create new rules of competition. Res. Technol. Manag. 2013, 56, 12-16. [CrossRef]

5. Lu, Y.; Wang, H.; Xu, X. ManuService ontology: A product data model for service-oriented business interactions in a cloud manufacturing environment. J. Intell. Manuf. 2016, 1-18. [CrossRef]

6. D'aveni, R.A. 3-D printing will change the world. Harv. Bus. Rev. 2013, 91, 34-35.

7. Kagermann, H.; Helbig, J.; Hellinger, A.; Wahlster, W. Recommendations for Implementing the Strategic Initiative INDUSTRIE 4.0: Securing the Future of German Manufacturing Industry; final report of the Industrie 4.0 Working Group; Forschungsunion: Berlin, Germany, 2013.

8. Bughin, J.; Chui, M.; Manyika, J. Clouds, big data, and smart assets: Ten tech-enabled business trends to watch. McKinsey Q. 2010, 56, 75-86.

9. Meier, M.; Seidelmann, J.; Mezgár, I. ManuCloud: The next-generation manufacturing as a service environment. ERCIM News 2010, 83, 33-34.

10. Kim, H.-J. Bounds for parallel machine scheduling with predefined parts of jobs and setup time. Ann. Oper. Res. 2018, 261, 401-412. [CrossRef]

11. Chopra, S.; Meindl, P. Supply chain management. Strategy, planning \& operation. In Das Summa Summarum des Manage; Gabler: Wiesbaden, Germany, 2007; pp. 265-275.

12. Ravindran, A.R.; Warsing, D.P., Jr. Supply Chain Engineering: Models and Applications; CRC Press: Boca Raton, FL, USA, 2012.

13. Noori, H.; Lee, W.B. Factory-on-demand and smart supply chains: The next challenge. Int. J. Manuf. Technol. Manag. 2002, 4, 372-383. [CrossRef]

14. Noori, H.; Lee, W.B. Dispersed network manufacturing: Adapting SMEs to compete on the global scale. Int. J. Manuf. Technol. Manag. 2006, 17, 1022-1041. [CrossRef]

15. Camarinha-Matos, L.M.; Afsarmanesh, H. The emerging discipline of collaborative networks. In Working Conference on Virtual Enterprises; Springer: Boston, MA, USA, 2004; pp. 3-16.

16. Camarinha-Matos, L.M.; Afsarmanesh, H. Collaborative networks: A new scientific discipline. J. Intell. Manuf. 2005, 16, 439-452. [CrossRef]

17. Gunasekaran, A.; Lai, K.-H.; Cheng, T.E. Responsive supply chain: A competitive strategy in a networked economy. Omega 2008, 36, 549-564. [CrossRef]

18. Kühnle, H. (Ed.) Distributed Manufacturing: Paradigm, Concepts, Solutions and Examples; Springer: New York, NY, USA, 2009. 
19. Gaynor, M.; Moulton, S.L.; Welsh, M.; LaCombe, E.; Rowan, A.; Wynne, J. Integrating wireless sensor networks with the grid. IEEE Internet Comput. 2004, 8, 32-39. [CrossRef]

20. Bendavid, Y.; Cassivi, L. Bridging the gap between RFID/EPC concepts, technological requirements and supply chain e-business processes. J. Theor. Appl. J. Electron. Commer. Res. 2010, 5, 1-16. [CrossRef]

21. Bendavid, Y.; Cassivi, L. A 'living laboratory'environment for exploring innovative RFID-enabled supply chain management models. Int. J. Prod. Dev. 2012, 17, 94-118. [CrossRef]

22. Ivanov, D.; Sokolov, B. The inter-disciplinary modelling of supply chains in the context of collaborative multi-structural cyber-physical networks. J. Intell. Manuf. Technol. Manag. 2012, 23, 976-997. [CrossRef]

23. Butner, K. The smarter supply chain of the future. Strategy Leadersh. 2010, 38, 22-31. [CrossRef]

24. Wu, L.; Yue, X.; Jin, A.; Yen, D.C. Smart supply chain management: A review and implications for future research. Int. J. Health Policy Manag. 2016, 27, 395-417. [CrossRef]

25. Wong, K.V.; Hernandez, A. A review of additive manufacturing. ISRN Mech. Eng. 2012. [CrossRef]

26. Berman, B. 3-D printing: The new industrial revolution. Bus. Horiz. 2012, 55, 155-162. [CrossRef]

27. Lu, L.; Sharf, A.; Zhao, H.; Wei, Y.; Fan, Q.; Chen, X.; Savoye, Y.; Tu, C.; Cohen-Or, D.; Chen, B. Build-to-last: Strength to weight 3D printed objects. ACM Trans. Graph. (TOG) 2014, 33, 97. [CrossRef]

28. Qin, Z.; Compton, B.G.; Lewis, J.A.; Buehler, M.J. Structural optimization of 3D-printed synthetic spider webs for high strength. Nat. Commun. 2015, 6, 7038. [CrossRef] [PubMed]

29. Beyer, C. Strategic implications of current trends in additive manufacturing. J. Manuf. Sci. Eng. 2014, 136, 064701. [CrossRef]

30. Zegard, T.; Paulino, G.H. Bridging topology optimization and additive manufacturing. Struct. Multidiscip. Optim. 2016, 53, 175-192. [CrossRef]

31. Berman, B. Should your firm adopt a mass customization strategy? Bus. Horiz. 2002, 45, 51-60. [CrossRef]

32. Insights, M.M. Layer-by-Layer: Opportunities in 3D Printing Technology Trends, Growth Drivers and the Emergence of Innovative Applications in 3D Printing. 2013. Available online: http:/ / www.marsdd.com/ wp-content/uploads/2014/04/MAR-CLT6965_3D-Printing_White_paper.pdf (accessed on 17 March 2018).

33. Campbell, T.; Williams, C.; Ivanova, O.; Garrett, B. Could 3D printing change the world. In Technologies, Potential, and Implications of Additive Manufacturing; Atlantic Council: Washington, DC, USA, 2011.

34. Bassoli, E.; Gatto, A.; Iuliano, L.; Grazia Violante, M. 3D printing technique applied to rapid casting. Rapid Prototyp. J. 2007, 13, 148-155. [CrossRef]

35. Sasson, A.; Johnson, J.C. The 3D printing order: Variability, supercenters and supply chain reconfigurations. Int. J. Phys. Distrib. Logist. Manag. 2016, 46, 82-94. [CrossRef]

36. Khan, A.; Turowski, K. A survey of current challenges in manufacturing industry and preparation for industry 4.0. In Proceedings of the First International Scientific Conference "Intelligent Information Technologies for Industry" (IITI'16); Springer: Cham, Switzerland, 2016; pp. 15-26.

37. Cotteleer, M.; Joyce, J. 3D opportunity: Additive manufacturing paths to performance, innovation, and growth. Deloitte Rev. 2014, 14, 5-19.

38. Liu, P.; Huang, S.H.; Mokasdar, A.; Zhou, H.; Hou, L. The impact of additive manufacturing in the aircraft spare parts supply chain: Supply chain operation reference (scor) model based analysis. Prod. Plan. Control 2014, 25, 1169-1181. [CrossRef]

39. Zhang, Y.; Huang, G.Q.; Qu, T.; Sun, S. Real-time work-in-progress management for ubiquitous manufacturing environment. In Cloud Manufacturing; Springer: London, UK, 2013; pp. 193-216.

40. Moghaddam, M.; Nof, S.Y. Real-time optimization and control mechanisms for collaborative demand and capacity sharing. Int. J. Prod. Econ. 2016, 171, 495-506. [CrossRef]

41. Hsieh, C.-C.; Wu, C.-H. Capacity allocation, ordering, and pricing decisions in a supply chain with demand and supply uncertainties. Eur. J. Oper. Res. 2008, 184, 667-684. [CrossRef]

42. Mohr, S.; Khan, O. 3D Printing and Supply chains of the Future. Innovations and Strategies for Logistics and Supply Chains. In Proceedings of the Hamburg International Conference of Logistics, Hamburg, Germany, 24-25 September 2015.

43. Seok, H.; Nof, S.Y. Collaborative capacity sharing among manufacturers on the same supply network horizontal layer for sustainable and balanced returns. Int. J. Prod. Res. 2014, 52, 1622-1643. [CrossRef]

44. Chen, F. Information sharing and supply chain coordination. Handb. Oper. Res. Manag. Sci. 2003, 11, 341-421.

45. Chan, H.K.; Chan, F.T. Effect of information sharing in supply chains with flexibility. Int. J. Prod. Res. 2009, 47, 213-232. [CrossRef] 
46. Jun, C.; Wei, M.Y. The research of supply chain information collaboration based on cloud computing. Procedia Environ. Sci. 2011, 10, 875-880. [CrossRef]

47. Brozovic, D. Strategic flexibility: A review of the literature. Int. J. Manag. Rev. 2018, 20, 3-31. [CrossRef]

48. Aaker, D.A.; Mascarenhas, B. The need for strategic flexibility. J. Bus. Strategy 1984, 5, 74-82. [CrossRef]

49. Sanchez, R. Strategic flexibility in product competition. Strat. Manag. J. 1995, 16, 135-159. [CrossRef]

50. Verdú-Jover, A.J.; Lloréns-Montes, F.J.; García-Morales, V.J. Environment-flexibility coalignment and performance: An analysis in large versus small firms. J. Small Bus. Manag. 2006, 44, 334-349. [CrossRef]

51. Scott, A.; Harrison, T.P. Additive manufacturing in an end-to-end supply chain setting. 3D Print. Addit. Manuf. 2015, 2, 65-77. [CrossRef]

52. Shirodkar, S.; Kempf, K. Supply chain collaboration through shared capacity models. Interfaces 2006, 36, 420-432. [CrossRef]

53. Barz, A.; Buer, T.; Haasis, H.-D. A study on the effects of additive manufacturing on the structure of supply networks. IFAC-PapersOnLine 2016, 49, 72-77. [CrossRef]

54. Emelogu, A.; Marufuzzaman, M.; Thompson, S.M.; Shamsaei, N.; Bian, L. Additive manufacturing of biomedical implants: A feasibility assessment via supply-chain cost analysis. Addit. Manuf. 2016, 11, 97-113. [CrossRef]

55. Ivanov, D.; Dolgui, A.; Sokolov, B.; Werner, F.; Ivanova, M. A dynamic model and an algorithm for short-term supply chain scheduling in the smart factory industry 4.0. Int. J. Prod. Res. 2016, 54, 386-402. [CrossRef]

56. Zukin, M.; Dalcol, P.R. Manufacturing flexibility: Assessing managerial perception and utilization. Int. J. Flex. Manuf. Syst. 2000, 12, 5-23. [CrossRef]

(C) 2018 by the authors. Licensee MDPI, Basel, Switzerland. This article is an open access article distributed under the terms and conditions of the Creative Commons Attribution (CC BY) license (http:/ / creativecommons.org/licenses/by/4.0/). 